\title{
Extensão universitária, comunicação e divulgação científica: A experiência do Jornal Universitário UENF ONLINE (2002-2012)
}

\author{
Marcelo Carlos Gantos ${ }^{1}$, Bárbara Martins Zaganell ${ }^{2}$
}

RESUMO: O Jornal Universitário Online (JUOL), da Universidade Estadual do Norte Fluminense Darcy Ribeiro (UENF), promove a preservação da memória científica da instituição e o estímulo à Compreensão Pública da Ciência por meio da produção mensal de informações para a internet em forma de textos, vídeos, sons e imagens. Assim, pretende-se neste artigo compartilhar o conhecimento de divulgação científica acerca deste trabalho e os resultados alcançados entre 2002 e 2012.

Palavras chave: Comunicação, divulgação científica, extensão inovadora, mídia eletrônica.

Áreas temáticas: Comunicação, teorias e metodologias em extensão.

\footnotetext{
${ }^{1}$ Professor Associado e Coordenador do Projeto e da UESI/Unidade Experimental de Som e Imagem/ LEEA-Laboratório de Estudos do Espaço Antôpico/CCH (E-mail: marcelo.gantos@pq.cnpq.br).

2 Jornalista e mestra do Programa de Pós- Graduação em Políticas Sócias/UENF CAPES (E-mail: barbarazaganelli@hotmail.com).
} 


\section{University extension, scientific communication and diffu- sion: The experience of official ONLINE UENF University (2002-2012)}

ABSTRACT: The University Journal online (JUOL) of the State University of North Fluminense Darcy Ribeiro (UENF) promotes the preservation of the memory of the scientific institution and the stimulation of the Public Understanding of Science through the producing information in the form of text, video, sounds and images disseminated by INTERNET. Thus, this article aims to share the knowledge of this work of scientific and achievements between 2002 and 2012.

Keywords: Communication, electronic media, innovative extension, scientific disclosure.

Thematic areas: Communication, theories and methodologies in extension.

\section{Extensión universitaria, comunicación y divulgación cien- tífica: La experiencia de la Universidad UENF ONLINE ofi- cial (2002-2012)}

RESUMEN: El funcionario de la universidad en línea (JUOL), la Universidad Estatal del Norte Fluminense Darcy Ribeiro (UENF), promueve la preservación de la memoria científica de la institución y la estimulación de la Comprensión Pública de la Ciencia mediante la producción de información mensual a Internet en forma de textos, vídeos, sonidos e imágenes. Por lo tanto, este artículo tiene como objetivo compartir el conocimiento científico acerca de este trabajo y los resultados obtenidos entre 2002 y 2012.

Palabras clave: Comunicación, extensión innovadora, la divulgación científica, los medios electrónicos.

Áreas temáticas: Comunicación, teorías y metodologías de extensión. 


\section{INTRODUÇÃO}

Desde os finais do século XX, acompanha-se uma manobra estratégica na sociedade brasileira de transferência do meio técnico-científico para os novos meios e serviços eletrônicos de produção, gestão e comunicação do conhecimento. Esta conjuntura estimula no âmbito acadêmico uma complexa e ainda inacabada operação de re-transcrição de hábitos, saberes e instituições. Mais que isso, este contexto impõe uma urgente e imperiosa tarefa de adaptação e reconfiguração dos nossos domínios de conhecimento, estruturas e práticas cognitivas e comunicativas adaptadas às novas possibilidades abertas pela globalização e a consolidação da sociedade da informação ${ }^{1}$ como âmbito de ressignificação da vida nas universidades e de suas ações educativas, investigativas e extensionistas.

Diante desse cenário em transformação, e impulsionado pela renovação e fortalecimento do campo acadêmico da Extensão Universitária no país, em 2002 surgiu como projeto de pesquisa e desenvolvimento junto à Pró-Reitoria de Extensão (PROEX) da Universidade Estadual do Norte Fluminense, o Jornal Universitário (JUOL) da UENF on line ${ }^{2}$. A iniciativa configurou-se como um desafio prático de escala local para as novas possibilidades comunicacionais abertas pelo processo sociotécnico de mudança paradigmática inaugurado pela revolução digital que consolidou a mídia digital como forma de comunicação dominante.

Uma década depois, o JUOL se mantém como uma iniciativa de pesquisa em extensão e desenvolvimento comunicacional digital, embrião da televisão da UENF, sendo realizado por uma equipe interdisciplinar composta por estudantes (bolsistas e voluntários), técnicos e professores vinculados à Unidade Experimental de Som e Imagem (UESI) do Centro de Ciências do Homem (CCH). Em 2002, recebeu financiamento da Fundação de Amparo à Pesquisa do Estado do Rio de Janeiro (FAPERJ) possibilitando a criação do Canal de Televisão Universitário (hoje UNITV Campos) ${ }^{3}$ e conjuntamente com uma sensível melhoria na sua infraestrutura. Vale apontar que ambas as experiências foram idealizadas como etapas de um projeto de comunicação articulado e, sobretudo, nasceram configuradas como domínios de informação independentes, isto é, sem a participação da reitoria da universidade e abertas para a gestão colaborativa e experimentação de linguagens. Aos poucos, o horizonte das ações do projeto pautou-se em ampliar e expor a participação da comunidade acadêmica no campo comunicacional com o intuito de contribuir na democratização dos canais de acesso ao conhecimento e a difusão da Ciência, Tecnologia e Inovação (CT\&I) da instituição. 
Destaca-se ainda que, como o JUOL encontra-se inserido e disponibilizado na estrutura do site da instituição. Com isso, pretende-se que todo cidadão curioso e com recursos telemáticos mínimos (computador e internet) tenha garantido livremente o acesso às informações produzidas e publicadas sobre a vida na universidade em forma de textos, vídeos, sons e imagens. A ideia é fazer com que o JUOL seja percebido como um veículo público e descentralizado de comunicação e difusão eletrônica das informações produzidas pela comunidade universitária, já que a mídia empresarial não divulga de modo expressivo o mundo da ciência, da educação e a cultura universitária.

Mesmo com as dificuldades enfrentadas ao longo do tempo, comuns a qualquer empreendimento extensionista na esfera pública, numa década de atuação o JUOL continua como o único divulgador independente da CT\&I no âmbito local. Nessa história, o viés participativo, colaborativo e solidário proveniente da extensão universitária, juntou-se com as possibilidades criativas da linguagem audiovisual e as potencialidades da comunicação eletrônica para compor um modo próprio de fazer a experiência da interiorização da divulgação científica, numa universidade de escala pequena e localizada numa região postergada do Estado do Rio de Janeiro. A trajetória do JUOL levou-o a se fortalecer com os avatares institucionais e potenciar sua condição periférica como foco para se reinventar no tempo perante os desafios do cenário universitário fluminense, conseguindo atingir níveis aceitáveis de produção e de qualidade, regularidade e visibilidade ao ponto de, em 2012, ter sido identificado e convidado a participar da Coleção Memória Nacional ${ }^{4}$.

\section{O MARCO INSTITUCIONAL E O CONTEXTO DO JUOL}

Fundada em 1993 em Campos dos Goytacazes ${ }^{5}$, no Norte Fluminense, a UENF foi idealizada por Darcy Ribeiro, e fez-se herdeira de um singular patrimônio histórico e cultural local, integrando antigas tradições com as novas perspectivas nos domínios das ciências, tecnologias e humanidades. Há duas décadas, a instituição é ampliada à luz de uma política de expansão dialogal Universidade/ Sociedade no que tange à produção de conhecimentos e transferência de tecnologias para sua comunidade. Basicamente, a instituição é estruturada em quarto centros: Ciências Humanas $(\mathrm{CCH})$, Biociências e Biotecnologia (CBB), Ciências e Tecnologias Agropecuárias (CCTA) e Ciência e Tecnologias (CCT). Ao todo, são 17 cursos de graduação - sendo 11 Bacharelados (em tempo integral), 04 Licenciaturas (noturnas) e 02 cursos de Licenciatura a Distância - e 15 Programas de Pós-Graduação, entre Mestrados e Doutorados, che- 
gando a 84 grupos de Pesquisa cadastrados no CNPq. Para se ter uma ideia, são cerca de 4,5 mil estudantes e 800 servidores, entre professores e técnico-administrativos.

Em 2008, foi reconhecida pelo MEC como uma das 15 melhores universidades brasileiras, ficando em $12 .^{\circ}$ lugar no ranking nacional baseado no Índice Geral de Cursos da Instituição (IGC) ${ }^{6}$. No mesmo ano, recebeu o Prêmio Nacional de Educação em Direitos Humanos, categoria Extensão Universitária, concedido pela Organização dos Estados Ibero-americanos para a Educação, a Ciência e a Cultura (OEI), o Ministério da Educação (MEC), em parceria com o Ministério da Educação (MEC) e a Secretaria Especial de Direitos Humanos da Presidência da República (SEDH), com patrocínio da Fundação SM. De 2009 até 2013, a UENF permanece entre as 15 melhores universidades brasileiras, sendo uma das Instituições de Ensino Superior (IES) mais bem ranqueadas do Estado do Rio de Janeiro.

Para compreender o papel do JUOL, principalmente na escala regional, é necessário compreender o contexto econômico, político e social o qual está inserido. A cidade de Campos dos Goytacazes, sede da UENF, é o principal município da Região Norte Fluminense, mas encontra-se reagindo a um processo de decadência econômica. Fato que parece ser mais devido à melhoria dos aspectos macroeconômicos nacionais do que devido ao próprio dinamismo das atividades econômicas locais vinculadas no presente, fundamentalmente, a riqueza petroleira concentrada na Bacia de Campos. Embora tenha apresentado de 2007 para 2008, segundo o Instituto Brasileiro de Geografia e Estatística (IBGE) ${ }^{7}$, o maior ganho de participação percentual no PIB do país, entre os municípios com pelo menos $0,5 \%$ do PIB nacional, devido ao aumento de produção de petróleo e gás natural e à alta do preço do petróleo, verifica-se a existência de múltiplas carências estruturais na Região. O Índice de Desenvolvimento Humano na última década, por exemplo, girou em torno de 0,7, estando entre os piores índices no ranking estadual. Se comparado aos índices das demais regiões do Estado do Rio de Janeiro, o progresso pode ser considerado para este estudo instável e letárgico.

Acredita-se assim que a superação de grande parte dessas carências e desigualdades sociais depende de uma contínua ampliação da competitividade das atividades econômicas já consolidadas nos municípios. Deste modo, as atividades de inclusão digital e desenvolvimento tecnológico via extensão da UENF adquirem uma dimensão regional estratégica. Por isso, a universidade vem trabalhando, simultaneamente, em várias frentes: favorecendo o investimento no aumento do nível de escolaridade e da qualificação dos trabalhadores já existentes no mercado de trabalho formal, bem como 
na promoção e geração de oportunidades para os que ainda não ingressarão nele. Nesse ponto, o processo deve ser acompanhado pelo esforço institucional no estreitamento da relação universidade/ sociedade. É justamente nessa instância, onde cresce a relevância social do JUOL como uma iniciativa inclusiva que promove um espaço comunicativo alternativo ao monopólio da mídia corporativa para realizar a divulgação do conhecimento científico, tecnológico e cultural, desenvolvendo simultaneamente ferramentas inovadoras no marco da Lei de Inovação do Estado do Rio de Janeiro ${ }^{8}$. O foco do acionar do JUOL está em cooperar nos processos de inclusão (digital-social) via letramento científico, principalmente, atraindo a participação e interesse dos jovens da região, vistos como atores sociais fundamentais para promover e aproveitar as transformações socioeconômicas em andamento.

Percebe-se que o destino do desenvolvimento dos municípios dessa região encontra-se nas mãos dos milhares de jovens estudantes que hoje cursam o Ensino Médio e Universitário. Mas para que o desenvolvimento possa despontar, entende-se que a juventude precisa qualificar-se e estar informada, motivada e conhecer a universidade. Isto é, é preciso identificar-se com suas atividades como campo de possibilidades profissionais e, de sobremaneira, visualizar e compreender a importância da esfera da CT\&I para desenho do futuro deles no mercado de trabalho e, de modo geral, no mundo da vida contemporânea. Assim, observa-se que as características sociais demográficas e geográficas do Norte do Estado do Rio de Janeiro, associadas à importância crescente da UENF como polo de irradiação do conhecimento e formação cidadã, definem um terreno fértil para o fomento da Cultura Científica. No cenário descrito, a mídia eletrônica consorciada com o audiovisual opera como um importante elemento de inclusão digital e estratégia comunicativa. Ambos constituem uma das modalidades preferidas para atrair e cativar o interesse do público juvenil.

\section{AS TENSÕES E OS DESAFIOS DAS MEDIAÇÕES ENTRE CIÊNCIA, TECNOLOGIA E INOVAÇÃÓ NO SÉCULO XXI}

Os avanços CT\&I trazem benefícios incontestáveis em diversas áreas da vida do ser humano. São inúmeras as contribuições deixadas pelas pesquisas científicas e tecnológicas nos campos social e econômico. Nesse contexto, o protagonismo do Brasil nas últimas décadas cresceu e passou a produzir e a investir cada vez mais em pesquisas, conforme os dados do Ministério da Ciência e Tecnologia (MCT) de 2010. Os números são favoráveis ao Brasil em relação 
ao crescimento de pesquisas tanto em quantidade quanto em qualidade. No ranking de produção científica, apontado pelo MCT, o país ocupa o $13^{\circ}$ lugar sendo responsável pela formação de cerca de 10 mil doutores por ano. Além disso, entre 2006 e 2008, o número de artigos publicados em revistas internacionais especializadas aumentou em 56\%. Já a taxa de crescimento na elaboração de trabalhos científicos foi de $8 \%$ ao ano, enquanto a média mundial estava em $2 \%$. E, para finalizar, o número de estudantes de mestrado e doutorado - responsáveis pelo maior volume de produção científica no Brasil - é dez vezes maior do que há 20 anos. Embora os dados sejam promissores para o país apontando que há um investimento e um desenvolvimento científico-tecnológico em fase crescente, observa-se comparativamente que o mesmo não acontece com o desenvolvimento social.

Esse descompasso entre o níveis de desenvolvimento científico-tecnológico e o desenvolvimento social está relacionado principalmente à fatores históricos da desigualdade e déficit de cidadania no pais, fatores que indiretamente refletem a carência de divulgação e cultura científica na população. Dito de outra forma: há barreiras de acesso e entraves entre os estudos desenvolvidos nas universidades e em outras instituições integradas ao sistema de pesquisa nacional e a informação e compreensão pública da maioria da sociedade excluída desse direito fundamental. Authier-Revuz (1998) assinala que a Divulgação Científica consiste em colocar de forma acessível ao grande público o resultado das pesquisas científicas. E, para que isso ocorra, é fundamental que as informações sejam transmitidas e universalizadas sempre de forma clara, simples, direta e de fácil entendimento. Segundo Calvo Hernando (2000), o papel da Divulgação Científica tem dois objetivos principais: um ligado ao conhecimento, que é comunicar ao público os avanços científicos da atualidade, e outro ligado à ação, isto é, à atuação social em relação às consequências que o desenvolvimento científico e tecnológico pode resultar. Assim, levando em consideração essas definições, postulamos que a Divulgação Científica, enquanto popularização da Ciência deve agir como instrumento de inclusão social e, por isso, deve-se propor o desafio de tentar atingir com eficácia a maior quantidade de camadas e faixas etárias da sociedade.

A complexidade do debate sobre a eficácia de nossa proposta comunicacional começa com a incapacidade de definir com precisão o que é a Ciência. É importante destacar que não existe unanimidade entre os diversos autores sobre a conceituação da Ciência, já que ela é histórica e muda de acordo com o seu próprio desenvolvimento (ALBERGUINI, 2007). Barros (2003) é um dos autores que defende este ponto de vista e explica que o processo de constante transfor- 
mação está ligado à própria essência da Ciência. Isto é, a Ciência não pode se estagnar para de evoluir e, com isso, o significado é mutável. Ou seja, as observações de novos fenômenos ou a explicação de fatos já conhecidos levam a um caráter de constante transformação e, por isso, não consegue manter uma unidade temporal ${ }^{9}$ sendo o significado da Ciência parcial e provisório. Sobre isso, Alberguini (2007) destaca, inclusive, que existe uma diferença no valor dado à Ciência. De acordo com as matrizes disciplinares - a Filosofia da Ciência, a História, a Sociologia do Conhecimento e a Sociologia da Ciência - o olhar e o interesse sobre a Ciência muda.

O foco da Filosofia da Ciência, por exemplo, é a forma como a Ciência foi concebida e operacionalizada para então conseguir submetê-la a uma medição estatística. De outro ângulo, a corrente histórica analisa o processo de desenvolvimento ao longo dos anos, para tentar apontar um significado para o termo. Essa linha pontua que a Ciência passou por três etapas: Amateurs, ou seja, Amadores (entre 1600 e 1800), período em que a Ciência era realizada fora de universidades, de instituições governamentais e do governo; Acadêmica (de 1800-1940), época em que se passou a dar maior atenção à formação técnica dos pesquisadores e Profissional, que corresponde à etapa atual (depois de 1940), caracterizada pelo aumento gradual dos esforços dos cientistas em dar aplicabilidade e utilidade ao conhecimento científico e da inserção dos pesquisadores em grandes grupos. Existem também os pesquisadores que seguem a corrente da Sociologia do Conhecimento que acreditam que a Ciência muda de acordo com o contexto social. Por fim, a Sociologia da Ciência analisa o termo enquanto estrutura institucional, estudando os grupos de pesquisa e as interações no laboratório, estando incluído nesta concepção, o próprio conhecimento científico dentro de seu objeto de estudo (DAGNINO \& THOMAS, 2002). Ao apontar essa gama de possibilidades e dimensões para delimitar os contornos da Ciência, pode-se entender um pouco essa dificuldade da compreensão pública acerca do termo e seus desdobramentos para a construção de uma mediação comunicativa efetiva entre significados, práticas e sujeitos.

Outro fator que prejudica a Compreensão pública da Ciência ${ }^{10}$ segundo o ponto de vista deste trabalho, é a distância, para não se falar em barreira, estabelecida entre o conhecimento popular e o científico, muitas vezes, devido ao mito criado e cultuado por profissionais da Ciência e a Comunicação acerca do termo. Segundo Mendonça (1996), o termo Ciência ainda permanece e é reproduzido vulgarmente como um mistério para muitas pessoas. Para não incorrer a equívocos, deve-se pontuar que esse afastamento entre o conhecimento científico ${ }^{11}$ e o popular não está atrelado ao fato da verdade 
ou da natureza do objeto, pois ambos estão ligados em relação à base do conhecimento. Nesse caso, distanciam-se quando a Ciência se especializa e se torna complexa. E isso acontece, de acordo com Alves (2003), pela forma de observação, do modo e do método e os instrumentos do conhecer. É preciso lembrar ainda que a Ciência é desenvolvida e controlada por seres humanos e não pode ser tratada como algo exato e mecânico (OLIVEIRA, 2009), tanto que o método por excelência da Ciência é o experimental, apoiado sempre em fatos reais e concretos. Em suma: a Ciência só pode afirmar aquilo que é autorizado pela experimentação e, por isso, pode ser falha.

Em consonância com o posicionamento da problematização sobre a definição da Ciência, no marco do JUOL aderimos a uma concepção sobre o significado do termo baseada em algumas referências teóricas (TRUJILLO, 1974; ANDER-EGG, 1978; MARTÍNEZ, 1998; ALVEZ, 2003; OLIVEIRA, 2009; MOTTA-ROTH, 2010). O objetivo dessa conceituação é ajustar e recortar a nossa compreensão e visualização do termo. Nesse sentido vale a pena voltar um pouco à origem latina do termo. A scientia significa conhecimento (CUNHA,1997). Por isso, Motta-roth (2010) define como "conhecimento de qualquer objeto ou fenômeno por intermédio da observação ordenada, identificação, descrição e explicação do fenômeno com base em um paradigma vigente". Do ponto de vista de Trujillo (1974, p.8), a Ciência compreende "um conjunto de atitudes e atividades racionais, dirigidas ao sistemático conhecimento com objetivo limitado, capaz de ser submetido à verificação". Outros autores propõem um conceito mais abrangente, como Ander-Egg (1978, p.15) que define como "um conjunto de conhecimentos racionais, certos ou prováveis, obtidos metodicamente sistematizados e verificáveis, que fazem referência a objetos de uma mesma natureza". Soma-se a esse quadro conceitual, o fato da Ciência só poder ser usada à produção ou à distribuição de bens e serviços somente de forma indireta e imediata (MARTINEZ, 1998). Isso faz, segundo Gil (2003), com que a Ciência seja entendida no seu componente meramente utilitário como elemento para a investigação e desenvolvimento tecnológico.

Nesse sentido, a utilidade da Tecnologia, ou melhor, do produto da Tecnologia, é mais facilmente compreendida pela sociedade já que é um meio indispensável para a satisfação das necessidades da população ou para o progressivo aumento das comodidades da sociedade (GIL, 2003). Barros (2003) destaca que a utilização do produto tecnológico não requer conhecimento dos princípios fundamentais que o regem. Sob esse olhar, propomos que Ciência seja entendida como um conjunto de conhecimento que está fundamentado e sistematizado de modo a ser testado experimentalmente, 
por meio de métodos, para verificar se as características comuns ou as leis que regem determinados eventos são verídicas ou não.

Apesar da baixa popularidade da Ciência em relação à Tecnologia, que é facilmente compreendida e aceita pela sociedade, é preciso reforçar a ideia que o grau de compreensão dos termos não está ligado à relevância para a sociedade. Prova disso, é que a diferença entre as nações ricas e pobres é feita pela capacidade de criar ou não o conhecimento científico (UNESCO, 2000). É interessante destacar ainda que exista uma relação de total dependência entre a Tecnologia e a Ciência, e vice-versa. Bazzo et al. (2003) e Alberguini (2007) explicam que a Tecnologia é usada para se referir aos sistemas desenvolvidos levando em conta o conhecimento científico. Em outros termos, a Tecnologia seria a ciência aplicada. Em contrapartida, Solla Price (1980) enfatiza que a Ciência sem a Tecnologia é estéril e conta que em diversos casos em que a sociedade pagou pela Tecnologia, devido ao retorno econômico imediato, e desprezou a Ciência, a Tecnologia entrou em "coma".

Rutherford e Algreen (1990) justificam a aproximação da Tecnologia maior à sociedade, se comparada a Ciência, por ela afetar o sistema social e cultural mais diretamente do que a pesquisa científica e, por isso, as implicações imediatas de seus sucessos e fracassos também refletem diretamente na atividade humana. Em contraposição a essa perspectiva apresentada, Bunge (1980) postula que a diferença básica entre a Ciência e a Tecnologia está nos objetivos. Enquanto a Ciência está preocupada em descobrir leis que possam explicar a realidade em sua totalidade, a Tecnologia está focada em controlar determinados setores da realidade, com a ajuda de todos os tipos de conhecimento, especialmente os científicos. Mas, como pontuado anteriormente, é preciso lembrar que a Tecnologia nasceu da ciência e, a partir do renascimento, aliou-se à técnica, com o fim de promover a junção entre o saber e o fazer. Por isso, para Martínez (1998), a Tecnologia pode ser definida como um conjunto de conhecimentos e métodos para o desenho, a produção e a distribuição de bens e serviços sendo, portanto, um sistema de conhecimentos técnicos. A partir dessas concepções, é também nesse contexto que deve ser pensada a Tecnologia. Ela não pode ser observada fora do modo de produção, como defendia Marx (MIRANDA, 2002). Essa percepção da definição do termo é compartilhada por Zancan (2000) que explica que a Tecnologia reflete e molda o sistema de valores, assim como estende nossas habilidades para transformar o mundo, sendo com isso uma ferramenta fundamental no desenvolvimento da civilização. A autora enfatiza ainda, e isso é interessante esclarecer, que a Tecnologia é muito mais que uma máquina, equipamento ou aparelho e, por isso, a materialidade ou imateriali- 
dade da tecnologia não é a principal diferença da Ciência.

Por fim, é importante incluir nesta discussão a noção de Inovação, que envolve um fenômeno muito mais amplo do que a Tecnologia e a Ciência, mas que as inter-relaciona. Segundo Saenz e Souza Paula (2002), a Inovação pode ser entendida como a introdução de uma Tecnologia na prática social, isto é, é o resultado da combinação de necessidades sociais e demandas do mercado com os meios científicos e tecnológicos para resolvê-las levando a um processo que depende da adesão e a difusão desses eventos pela pluralidade dos elementos de um determinado espaço social. Assim, em suma, o projeto JUOL instala-se na interseção do debate entre CT\&I e sociedade, um espaço de combate de ideias onde a extensão universitária e a comunicação adquirem cada dia maior relevância e visibilidade como agentes de um novo processo de mediação social entre os diversos atores, discursos, as demandas sociais e as novas formas de cidadania em construção.

\section{O ACESSO À INFORMAÇÃO SOBRE CT\&I COMO UM DIREITO DO CIDADÃO}

Alinhados às perspectivas dessas análises, é interessante atentar-se para um fato preocupante: independente da Ciência e da Tecnologia serem potencialmente capazes de definir o futuro de um povo, elas são paradoxalmente excludentes (SANCHS, 2000). É possível perceber que nem todos têm acesso ao uso dessas ferramentas, o que leva a diversas entidades, como a UNESCO (2000), a se anteciparem e preocuparem com o problema da exclusão de uma parcela considerável da população ao acesso desses bens tecnológicos, criando inclusive conceitos como o de exclusão digital. Assim o desígnio que subscreve que tanto a Ciência quanto a Tecnologia devem ser aplicadas para aumentar não apenas a competitividade e o emprego, como também a justiça social. Uma concepção compreendida e estimulada no projeto JUOL.

Para Motta-Roth (2009b), a relevância da comunicação sobre as pesquisas científicas pode ser vista de três aspectos: a obrigação dos meios de comunicação de informar a sociedade sobre o avanço acadêmico, a responsabilidade do autor em explicar os princípios e conceitos para que a sociedade avance na transformação conjunta do conhecimento e, por fim, a necessidade da sociedade entender a relevância da pesquisa para que continue financiando-a. Acerca disso, chama-se a atenção para outros dois fatores explicativos. É preciso lembrar que a divulgação e a compreensão da população sobre os avanços da CT\&I consistem numa das maneiras de se prestar 
contas a quem financia, indiretamente por meio de impostos, os estudos científicos desenvolvidos na esfera pública. É preciso destacar ainda, como acertadamente expôs Mourão (2003), que o conhecimento só é conhecimento se compartilhado. Assim, o acesso a ele precisa ser democratizado para ser legitimado. Diante dessa exposição inicial, Motta-Roth (2009b, p.2) assinala que a divulgação e compreensão pública da ciência só podem ser concretizadas mediante o apoio

das forças econômicas e políticas da sociedade que consagrará qualquer área do conhecimento ou teoria como ciência (e trará reputação e ascensão profissional ao / à cientista), garantindo a continuidade ou a mudança de paradigmas (MOTTA-ROTH, 2009b, p.2).

Assim, é preciso enfatizar a importância do esforço das esferas públicas e privadas em prol da divulgação científica.

Em consonância com esse posicionamento, Blotta (2005, p.35) enfatiza ainda que existem princípios legais que garantem a liberdade à comunicação, como o artigo $5^{\circ}$ da constituição brasileira na qual estão expostos. O JUOL é partícipe do princípio constitucional que promove a livre circulação de ideias e opiniões que estimulem o desenvolvimento da dignidade da pessoa humana e da democracia social como um direito garantido em lei. No que concerne ao entendimento sobre o acesso à informação e o direito à comunicação, diferente das abordagens clássicas que enfocam sob o ângulo do direito ao acesso à informação ou como direito à liberdade de informação e de expressão desde sua formulação o JUOL vem mantendo a proposta de uma concepção que se renova ao incluir a dimensão do direito à comunicação enquanto acesso ao poder de comunicar (PERUZZO, 2011).

As liberdades de informação e expressão postas em questão na atualidade não dizem respeito apenas ao acesso da pessoa à informação como receptor, nem apenas no direito de expressar-se por "quaisquer meios" - o que soa vago, mas de assegurar o direito de acesso do cidadão e de suas organizações coletivas aos meios de comunicação social na condição de emissores - produtores e difusores - de conteúdos. Trata-se assim de promover a democratização do poder $^{12}$ de comunicar, transformando o conceito de direito à comunicação. Assim,

O direito à informação, antecipado na Declaração de $1789^{13}$ (LAFER, 1991), está contemplado no Artigo $19^{\circ}$ da Declaração Universal dos Direitos do Homem, de 1948, que diz "todo o indivíduo tem direito à liberdade de opinião e de expressão, o que implica o direito 
de não ser inquietado pelas suas opiniões e o de procurar, receber e difundir, sem consideração de fronteiras, informações e ideias por quaisquer meios de expressão" (LAFER, 1991, p.241). Para Seclaender (1991, p.149), o direito de liberdade de expressão está atrelado ao direito à informação.

Apesar disto, não convém esquecer que, embora tenham gerado alguns obstáculos à ideia de direito à informação, a Declaração e os outros documentos aqui citados deram uma contribuição decisiva a tal processo. De fato, ao adotarem a concepção da liberdade de informação como o somatório da "liberdade de transmitir" ou "comunicar" com a de "procurar e receber" informações, acabaram eles preparando terreno para a aparição, no mundo jurídico, de um novo direito subjetivo bifronte, de um direito abrangente o bastante para estender a proteção do ordenamento não só à atividade jornalística, mas também ao interesse dos governados de saber, por meio destes e dos órgãos estatais, tudo o que se refira à condução dos negócios públicos.

Desse modo, esse apelo à participação da população nas atividades científicas por meio dos veículos de comunicação, embora alternativos como este do JUOL, tende a se constituir para Albagli (1996) em uma forma de fornecer uma via alternativa de controle social maior do público leigo sobre os impactos da CT\&I na vida cotidiana, sugerindo a participação da sociedade sobre questões de caráter social, tecnológico e científico para a solução de problemas resultantes de ações passadas, que ainda atingem e angustiam a população.

\section{A CONVERGÊNCIA MIDIÁTICA COMO ALAVANCA DA DIVULGAÇÃO CIENTÍFICA}

A informática e a internet consorciadas ao vídeo, como modo de produção audiovisual e à TV como meio de comunicação de massa, consolidaram-se ao longo desta década na chamada convergência midiática que as colocam como ferramentas privilegiadas de instrumentalização eletrônica nos processos centrais do conhecimento contemporâneo: ensino-aprendizagem, capacitação, formação e informação sociocultural da população e exercício da cidadania ${ }^{14}$. Esses três grandes territórios de atividades formam atualmente a indústria da informação:

a) a informática;

b) as telecomunicações (que juntas constituem a telemática);

c) o audiovisual.

Os que analisam as práticas vinculadas desta indústria classificam 
as competências de cada área segundo o critério do "saber fazer", correspondendo cada um deles a três domínios independentes, embora complementares: o da criação de imagens e sons, o do tratamento numérico da informação e o da difusão. A produção audiovisual, incorporada à indústria da informação, configura um dos campos de maior crescimento e importância do cenário tecnológico contemporâneo.

É preciso relembrar que há algumas décadas foi preconizado, pelos teóricos da comunicação, que a civilização democrática emergente somente se salvaria ao conseguir fazer da linguagem da imagem uma provocação à reflexão. Este desafio vem estimulando desde suas origens a proposta do JUOL, um projeto de comunicação audiovisual que surgiu comprometido com os valores do desenvolvimento humano e a promoção da emancipação social através do acesso à informação científica e a educação da sensibilidade.

Partindo da premissa da indissociabilidade entre ensino-pesquisa e extensão e o inserido no contexto comunicacional da extensão universitária brasileira, na formulação original do JUOL considerou-se prioritário cooperar no fortalecimento e articulação das duas esferas de interesses representadas pela comunicação eletrônica e as estratégias de divulgação científica. Trabalhou-se no sentido de propiciar gerar ações concretas de popularização da ciência, a tecnologia (MASSARANI, 2002) e a cultura, explorando novas possibilidades de linguagens, estilos de formatação de conteúdos e mediações com o público. Nessa direção, optou-se por estruturar o trabalho via convergência midiática (informática, internet e vídeo) pensada como estratégia de produção e comunicação audiovisual, somando as possibilidades da TV e o boom da telefonia celular e das redes sociais como meios trans-midiáticos. Este conjunto de elementos é considerado, ainda uma década depois de sua formulação, como mediações privilegiadas da atual fase de instrumentalização eletrônica dos processos centrais do conhecimento, que englobam diversas modalidades de ensino-aprendizagem, formação, capacitação e informação da população. Todos os elementos referidos funcionam como estruturantes e facilitadores das formas emergentes da exercer a cidadania contemporânea (BERNARDES, 2007).

Apesar dos discursos institucionais, as tendências e os indicadores assinalarem um futuro promissor para as novas mediações e os correlatos processos de reconfiguração de lugares, saberes e organizações, existe ainda uma lenta assimilação das novas tecnológicas de informação e comunicação ao cotidiano acadêmico. Os motivos desta preguiça envolvem questões de diversos gêneros e diferentes níveis de discussão. Do ponto de vista acadêmico, vale destacar a existência de uma notável defasagem curricular na quase totalidade dos cursos de graduação das universidades do país com respeito à 
inserção da temática referida nos planos de estudo. Este fenômeno se evidencia no déficit de oferta de disciplinas "instrumentais" e até introdutórias nos ciclos iniciais de formação, dedicadas a discutir a natureza e impacto na produção do conhecimento das transformações sociotécnicas e ainda suas apropriações metodológicas e usos nos diversos domínios científicos. Esta situação reduz as possibilidades, em sala de aula e nos ambientes de pesquisa e intervenção social, de promover uma relação pedagógica atualizada que articule na prática cotidiana os conhecimentos e potencialidades derivados da ampliação do acesso e uso das novas tecnologias.

Paralelamente aos desarranjos observados e a recente irrupção da mídia eletrônica como possibilidade da extensão universitária, a atual configuração converte a todos os participantes que incursionam nestes territórios híbridos pautados pela convergência midiática, em verdadeiros "aprendizes de feiticeiros". Numa outra escala pode-se destacar a limitação de infraestrutura adequada e financiamento específico para a prática audiovisual dentro das universidades e, sobretudo, a carência de professores pesquisadores capacitados nesse segmento, aptos para operacionalizar essa interface entre teoria e prática. Refere-se aqui a outro descompasso gerado pelos efeitos da revolução tecnológica nas instituições: o problema geracional entre nativos e migrantes digitais, uma brecha ainda persistente dentro dos quadros universitários. É prioritário renovar e expandir a universidade atualizando e recompondo seus recursos humanos, gerando ações de capacitação e promovendo a demanda de profissionais formados dentro do paradigma digital. São necessários perfis flexíveis e interdisciplinares, que atuem como integradores destes saberes e práticas e estejam prontos para promover a inclusão digital interna e gerar a demanda de recursos que sustentem ações e projetos inovadores. A mídia eletrônica, aliada à promoção da cultura científica no marco da extensão universitária, compõe um arranjo produtivo valioso que se constitui, pelas forças que envolvem, num domínio emergente de enorme projeção para cooperar na consolidação da Universidade Cidadã.

Assim o Jornal Universitário via internet fundou-se na confiança depositada nos princípios e valores elencados, alavancada nos processos e resultados cognitivos e técnicos possíveis de ser obtidos através da busca da convergência midiática como plataforma. Os fundamentos partiram do uso experimental do vídeo aplicado à pesquisa comunicacional, tanto na produção de estoques de informação científica tecnológica e acervos documentais, quanto no campo da docência superior e sua interface produtiva de materiais educativos. O JUOL foi imaginado e desenvolvido como um espaço privilegiado de cultivo da convergência midiática a serviço da co- 
municação científica e, ao mesmo tempo, concebido como alavanca política do processo de reconstrução e ressignificação da esfera pública por meio da extensão universitária.

O JUOL após uma década de existência trabalha para manter vivos e renovados seus objetivos que reforçam a busca da experimentação de novas linguagens e formatos de comunicação audiovisual, agora num cenário trans-midiático, como âncora, possibilitando fazer uma experiência de Divulgação Científica diferenciada, isto é, menos formal e atrativa para o público jovem e baseada no fomento do direito à informação como uma dupla via, de formação ética e cultural e de acesso à cidadania. Busca-se no dia a dia do trabalho de extensão desenvolver atividades de pesquisa, ensino e produção audiovisual que viabilizem a elaboração de notícias ${ }^{15}$ dedicadas à divulgação de assuntos referidos às ciências e tecnologias sociais, incluindo as artes, humanidades e a cultura geradas no território UENF.

Por outro lado, houve um esforço do projeto em estimular a renovação curricular no nível de graduação e pós-graduação com a formulação e inclusão de disciplinas novas. O propósito foi encurtar a brecha de conhecimento favorecendo o desenvolvimento articulado de competências linguísticas, estéticas e técnicas, aplicadas ao exercício de elaborar uma outra Divulgação Cientifica que estimule a sensibilidade e torne a informação mais atrativa, principalmente, para o público jovem.

\section{METODOLOGIA}

A repentina crise do canal universitário administrado pelo UESI pôs fim em agosto de 2003, depois de quase um ano de funcionamento, ao conteúdo da UENF que era veiculado no canal 16, da operadora local de TV por assinatura Adelphia Via Cabo. A interrupção desse processo levou o grupo a discutir formas alternativas de gestão para manter acesa as atividades e não desmotivar os alunos envolvidos no projeto. A solução surgiu da reconversão do projeto inicial, a partir dali, focado apenas na manutenção do jornal, na fomentação de outro arranjo produtivo baseado na revisão das estratégias gestão e comunicação. Deste modo atravessou-se no interior da UESI, sua unidade gestora, por uma fase conturbada de migração e readaptação da estrutura física e organizacional para acolher e incorporar o projeto e poder dar resposta técnica efetiva à demanda de aplicação de meios e serviços eletrônicos na gestão, produção e comunicação do jornal. Este percurso definiu um novo cenário de operações e serviu para pensar e ajustar ao mesmo tempo as opções técnicas do modelo metodológico desenhado. 
O desenvolvimento da infraestrutura audiovisual e técnica dedicada à TV universitária criou dentro da UESI, condições e princípios necessários para concepção, elaboração, administração e disseminação de conteúdos e repertórios documentais que seriam adaptados para outras formas e suportes de mídia. No âmbito metodológico e pedagógico, a desarticulação do projeto da TV Universitária possibilitou no curto prazo um movimento organizacional interno incipiente no plano curricular e de adequação do método de trabalho as novas demandas e possibilidades abertas. Esta transição foi aproveitada para capacitar e formar o alunado em novas competências técnicas que privilegiaram o aprimoramento da cultura visual mediante a prática de registro audiovisual (fotografia e vídeo) associado ao processamento digital de imagens. Complementarmente trabalhou-se no desenvolvimento das redes telemáticas e na adequação do espaço físico para incorporar equipamentos e suportes de comunicação. Assim, o conjunto de mudanças descritas nessa transição operativa acabou definindo outro desafio de ação e reflexão determinado pela potencialidade aberta pela confluência mediática, o trabalho colaborativo e a temática da divulgação científica como objeto e problema de pesquisa.

Estudos recentes realizados no marco da linha de pesquisa "Política, Cultura e Conhecimento", dentro do Programa de Pós-Graduação em Políticas Sociais do CCH /UENF, revelaram as diversas fases do impacto do processo de mutação na cultura dos jovens alunos a respeito das práticas tradicionais de leitura e sua relação com a cultura e divulgação científica. As pesquisas verificam a percepção do fenômeno de uma maciça migração do interesse e a atenção dos jovens para as novas formas de comunicação eletrônica associada ao uso ampliado de Internet e da portabilidade como referência cultural e estilo de sociabilidade. Um resultado satisfatório visto o declínio simultâneo do consumo de jornais tradicionais e revistas de ciência no mundo. No cenário descrito, a televisão ocupa o segundo lugar nas preferências dos jovens estudantes da mídia, fato que demonstra a vigência do paradigma audiovisual e da cultura da portabilidade como pauta cognitiva e de sociabilidade nova destas gerações. Esta referência sobre a mutação cultural do público local nos motivou a fortalecer a premissa original do JUOL de promover a adaptação e reconfiguração dos domínios, estruturas, práticas cognitivas e comunicativas. Se a origem da renovação do projeto do JUOL esteve marcada pela necessidade de superação de uma conjuntura adversa, o marco teórico e metodológico do projeto foi modelado para alavancar, testar e aplicar socialmente o conhecimento resultante da pesquisa científica.

O conceito de "convergência midiática" foi entendido e introduzido como uma tendência que sintetiza e valoriza a opção pela conjunção do modo de produzir da televisão, apoiado pelo suporte da 
informática e as possibilidades abertas pela Internet. Na escolha do tema de trabalho, usou-se a teoria do déficit informativo e do aproveitamento do capital de conhecimento científico e tecnológico acumulado e fechado na instituição como desafio epistêmico e empírico. Conto-se ao logo do tempo com a disposição de um pequeno grupo executor, sempre flutuante em função da dinâmica do projeto, de base multidisciplinar, formado majoritariamente por estudantes e servidores da instituição. O motor das indagações do projeto foi discutir, identificar e planejar as possibilidades de capitalizar, por meio do apelo à Divulgação Científica, os feitos e contributos da universidade em muitos casos, condenados ao efeito do "engajamento".

A metodologia praticada apoia-se, por um lado, nas técnicas pedagógicas audiovisuais baseadas nas artes do vídeo e nos fundamentos de uma comunicação à mobilização social e participação comunitária. Por outro lado, o método do JUOL se compõe de rotinas de produção que se desenvolvem a partir da escolha e experimentação de gêneros jornalísticos como, por exemplo, a reportagem audiovisual. Esta se caracteriza, com respeito a outros gêneros jornalísticos, por sua abertura à diversidade temática e pela flexibilidade formal para se adequar aos fins do projeto.

A equipe realizadora goza de uma grande liberdade oferecida pela reportagem, gênero que faz parte da vertente mais criativa e literária do jornalismo. É uma modalidade versátil, já que admite articular e incorporar múltiplos procedimentos e recursos. Pode, por exemplo, absorver outros gêneros jornalísticos informativos - como notícias, crônicas, entrevistas - de opinião e até projetos investigativos ou documentais. Além disso, pode assimilar parcial ou totalmente gêneros literários e artísticos - como novelas, ensaios ou teatro. A opção pela reportagem permite tematizar e simultaneamente dar conta de uma realidade cada vez mais completa, de maneira que o receptor contemporâneo, com diferentes necessidades e exigências, não só tenha a possibilidade de estar informado como também de conhecer as causas e motivações, os processos em si e a diversidade de interpretações que qualquer fato ou acontecimento pode gerar.

O trabalho do JUOL está programado em duas etapas, cada uma delas composta por fases de atividades e rotinas específicas:

\section{Primeira: Fase de Pré-Produção}

- Pesquisa e planejamento

- Visualização

- Organização da estrutura da reportagem documentária.

Nesta etapa são apurados e inventariados os eventos e os fatos 
em destaque na universidade, de maneira que a equipe procure equilibrar a pauta produzindo de forma equitativa matérias sobre os laboratórios de cada centro e os diversos campos científicos. Em seguida realiza-se a redação dos textos dos jornais que inclui o exercício de visualizar as matérias e, por fim, roteirizar. A última fase consiste no contato com o pesquisador mediante uma visita in loco que permite o agendamento das entrevistas juntamente com a fase de produção de imagens internas e externas e material documental adicional, que fazem parte da preparação da reportagem.

\section{Segunda: Produção}

- Filmagem, decupagem e edição

- Finalização

- Adequação da página eletrônica do JUOL

- Publicação eletrônica e arquivamento em mídia digital

Nesta etapa, faz-se o deslocamento da equipe de produção excepcionalmente composta de diretor de imagens, cinegrafistas, iluminadores, operadores de som e repórteres para a produção do material de campo. Na prática, e de acordo com a dimensão da reportagem, essas atribuições são geralmente repartidas e acumuladas numa equipe de quatro pessoas (cinegrafista/operador de câmara/diretor de imagens; operador de som; iluminador/assistente e repórter) para que possam ter agilidade ao gravar entrevistas (sonoras), cabeças, stand-ups e imagens auxiliares para a cobertura da produção de offs. São utilizados equipamentos como câmera, baterias, tripé, microfone de lapela, microfone, cabo de áudio, fitas e fonte de alimentação. O material filmado é gravado em cartões de memória e entregado para descarregar na edição na ilha, onde os editores importam toda gravação externa e fazem uma rápida decupagem, enquanto a equipe de estúdio grava a participação dos apresentadores. Os editores iniciam a montagem do material audiovisual até que o produto esteja completo, inserindo nele as identidades visuais da universidade, vinhetas, créditos, entre outras composições. Após a finalização do jornal e a visualização final no computador (IMac), o arquivo é exportado e convertido do formato MOV para AVI para reduzir o tamanho do arquivo. O produto é transportado para outra máquina $(\mathrm{PC})$ onde é feita a conversão do arquivo para WMV através de um programa codificador (vídeo encoder). Logo após, o arquivo é inserido no sistema e publicado na página da UENF, tornando-se acessível para o público pela internet. A última etapa do processo é a realização de uma cópia de segurança num dispositivo de memória externa, e o posterior arquivamento do material em mídia digital (DVD) para futuras exibições, emprés- 
timos, cópias e pesquisas de imagens.

De modo geral, as ferramentas usadas nas rotinas descritas, tanto de campo como de gabinete, definem um modelo de instrumentação eletrônica acessível tanto tecnicamente como economicamente. Ao longo de uma década de experiência, o projeto JUOL desenvolveu uma metodologia própria, on demand, preocupada em cada dia se tornar mais amigável, flexível e efetiva. Buscou-se eficiência conjugando rotinas de produção colaborativas com gêneros jornalísticos de interesse juvenil. A fórmula foi ajustada a uma proposta de Divulgação Científica despretensiosa no aspecto ritualístico e formal da Ciência, buscando a funcionalidade e a acessibilidade oferecida pela comunicação eletrônica com recursos, atualmente, disponíveis em qualquer meio acadêmico.

\section{RESULTADOS À VISTA}

O funcionamento do JUOL estimulou a oferta de disciplinas de apoio com o intuito de que ajudassem a equipe a desenvolver e ampliar o Jornal on line. As atividades pedagógicas prescritas de fundamentação teórica, ensino e prática das artes do vídeo, fotografia, roteirização para Divulgação Científica foram incluídas em disciplinas de graduação, como as "Técnicas de Pesquisa Visual I" e "Pedagogia da Imagem". A primeira funciona como disciplina instrumental e é oferecida alternadamente cada semestre do ano na grade do curso de graduação em Ciência Sociais, sendo aberta também ao alunado da UENF como tópico especial ou disciplina opcional. A segunda faz parte das disciplinas optativas da Licenciatura em Pedagogia e aborda aspectos de ordem teórica e de sensibilização para a formação de uma cultura visual no alunado. As disciplinas subsidiam com a pesquisa a geração de pautas para as reportagens e são apoiadas por atividades de campo onde são experimentadas as técnicas audiovisuais. Este trabalho pedagógico evidencia o papel do ensino como um importante estímulo à criatividade e desenvolvimento de novas vocações, tanto como mecanismo de captação de alunos para a manutenção e desenvolvimento do projeto.

Outro ponto de atenção acerca dos resultados é em relação ao estímulo ao agir colaborativo e interdisciplinar que o JUOL está realizando na comunidade acadêmica. Os candidatos provenientes de diversas carreiras se inscrevem inicialmente como voluntários no projeto e posteriormente na condição de bolsistas de extensão, cumprindo desta forma um processo preparatório que, muitas vezes, serve de pontapé inicial para a continuação de outras atividades acadêmicas, como trabalhos finais de graduação, mestrado e doutorado. Do ponto de vista do labor extensionista, destaca-se que os 
cidadãos da comunidade, seja esta interna ou externa à UENF, estão conseguindo ter acesso às informações científicas e atividades realizadas dentro da universidade com regularidade, mais frequência e profundidade nos assuntos pautados pelo JUOL, fazendo com isso que a informação circule e seja acessada, aumentando o grau de participação e compreensão de repertórios temáticos e aspectos da ciência que permaneciam guardados.

\section{CONCLUSÕES}

Verifica-se na experiência do JUOL que o projeto vem despertando a curiosidade pelo diálogo dos saberes e os fazeres em torno da comunicação dedicada à Divulgação Científica, mobilizando a cooperação interdisciplinar nos seus participantes e fortalecendo assim a esfera da Extensão no âmbito institucional e acadêmico da UENF. Na medida em que os atores envolvidos cotidianamente nas rotinas do trabalho desenvolvem juntos os conhecimentos, compartilham e trocam experiências, transformam o(s) modo(s) de ver e relacionar-se com a Ciência e a cultura acadêmica que os circunda modelando na esfera subjetiva sua identidade social.

Nesse contexto, as edições do JUOL, enquanto produtos acabados da atividade, refletem outra dimensão objetiva de avaliação desta atividade. A sequência temporal de produção do JUOL expõe no tempo índices de produtividade aceitáveis, dos quais sublinhamos a consolidação de um modelo metodológico participativo e dialógico que se traduz na escolha e tratamento dos assuntos abordados nas reportagens noticiadas. Mas a prática também nos alerta para as dificuldades e limitações objetivas existentes para integrar o agir cooperado num ambiente competitivo, individualista e meritocrático, como é o promovido pelo atual modelo acadêmico. Visto assim, o desafio atual do projeto não consiste apenas no número e qualidade técnica atingida pelo produto final, isto é, quantidade de jornais, a beleza das imagens, a prolixidade de sua edição, os acessos atingidos ou a clareza e eficácia da informação veiculada. O maior desafio é manter o legado do JUOL ao longo de sua trajetória, ou seja, a possibilidade de continuar educando a sensibilidade dos participantes numa vertente democrática do fazer colaborativo isenta e responsável, constituindo uma experiência pedagógica diferente.

Esta singularidade se baseia na ênfase outorgada à educação dos sentidos, não só nos âmbitos de uma comunicação que veicula mensagens educativas ou se propõe a uma releitura crítica da relação entre Ciência e sociedade, senão na busca intensa da renovação e ampliação constante do espaço que ocupa a extensão universitária. O projeto JUOL está focado em praticar e promover a indissociabilidade 
entre ensino-pesquisa-extensão, como estratégia comprovada para avançar na construção de vias horizontais de interlocução social. Elas surgiram e se nutriram de um encontro proposital entre a racionalidade estética, as tecnologias e as demandas de um agir comunicativo cidadão. Dessa conjugação deriva o legado mais genuíno e intangível do projeto, que em função de seu caráter processual, difuso e qualitativo torna-se difícil dimensionar, mas segue sendo de prioritária atenção e promoção na continuidade programática do projeto JUOL como valor humano indispensável na construção do modelo de universidade pública idealizado pelo Darcy Ribeiro para a UENF.

\section{REFERÊNCIAS BIBLIOGRÁFICAS}

ALBAGLI, S. Divulgação científica: informação científica para a cidadania? Ciência da informaçẫo, v.25, n.3, p.396-404, 1996.

ALBERGUINI, A.C. A Ciência nos Telejornais Brasileiros (O papel educativo e a compreensão pública da matéria 200 de CT\&I). Tese (doutorado) - Programa de Pós-Graduação em Comunicação Social em Umesp - Universidade Metodista de São Paulo, São Bernardo do Campo, São Paulo, 2007.

ALVES, R. Filosofia da ciência: introdução ao jogo e suas regras. São Paulo: Brasiliense, 2003.

ANDER-EGG, E. Introducción a lás técnicas de investigación social: para trabajadores sociales. 7.ed. Buenos Aires: Humanitas, 1978. Primeira Parte. Capítulo1.

AUTHIER-REVUZ, J. Palavras incertas: as não do dizer. In: Coleção Repertórios. São Paulo: Editora da Universidade Estadual de Campinas. UNICAMP, 1998.

BARROS, H.L. Museus e Ciência. In: SOUZA, C.M.; Marques, N.P.; Silveira, T.S. (Org.). A Comunicação Pública da Ciência. Taubaté São Paulo: Cabral Editora e Livraria Universitária, 2003.

BAZZO, W.A.; VON LINSINGEN, I.; PEREIRA, L.T.V. Introdução aos estudos CTS (Ciência, Tecnologia e Sociedade). Madri: Organização dos Estados Ibero-americanos, 2003.

BERNARDES, C. Hélio Costa diz que canal digital público é possível. Disponível em: <http://www2.camara.gov.br/homeagencia/materias.html?pk=100403 >. Acessado: 2 abr. 2007.

BOURDIEU, P. Para uma sociologia da ciência. 2.ed. Lisboa: Ática, 2008.

BUNGE, M. Ciência e desenvolvimento. Belo Horizonte: Editora Itatiaia, São Paulo: Editora da Universidade de São Paulo, 1980.

BLOTTA, V.S.L. A Comunicação social no atual estado democrático de direito: para um novo controle social da informação. Trabalho de Conclusão de Curso. Orientado pelo professor Luis Francisco Aguilar Cortez, Faculdade de Direito da Universidade Católica de Campinas, 2005. Disponível em: <http://www. direitoacomunicacao.org.br/index2.php?option=com_docman\&task=doc_ view\&gid=377\&Itemid=99999999 > . Acessado: 25 de out. 2012. 
BRASIL. Constituição Federal de 1891. Decreto no 52.795, de 31 de outubro de 1963. Aprova o regulamento dos serviços de radiodifusão. Diário Oficial da República Federativa do Brasil, Brasília, DF, 12. nov. 1963. Disponível em: <http://www.planalto.gov.br>. Acessado: 25 out. 2012.

CALVO HERNANDO, M. Educación y comunicación, un doble desafio de nuestro tiempo, 2004. Disponível em <http://www.manuelcalvohernando.es〉. Acessado: 10 dez. 2006.

CUNHA, A.G. Dicionário etimológico Nova Fronteira da língua portuguesa. Rio de Janeiro: Nova Fronteira, 1997.

DAGNINO, R.; THOMAS, H. (orgs.) Panorama dos estudos sobre Ciência, Tecnologia e Sociedade na América Latina. Taubaté/SP: Cabral Ed. e Livraria Universitária, 2002.

FRANSISCATO, C.E. Limites teóricos e metodológicos nos estudos sobre a noticiabilidade. Texto apresentado no $11^{\circ}$ Encontro Anual da Associação dos Programas de Pós-Graduação em Comunicação/COMPÓS, no Grupo de Trabalho 'Estudos de Jornalismo’. Rio de Janeiro (RJ), jun. 2002. Disponível em: <http:// www.ufrgs.br/gtjorna lismocompos/doc2002/francis cato2002.doc>. Acessado: 24 out. 2012.

GIL, F.B. Que imagem da ciência transmitiam os museus do século XIX?. In: SOUZA, C.M.; Marques, N.P.; Silveira, T.S. (Org.). A Comunicação Pública da Ciência. Taubaté, São Paulo: Cabral Editora e Livraria Universitária, 2003.

IBGE 2010 - Disponível em:<http://ibge.goc.br/cidadesat/dafault.php>. Acessado: 21 out. 2012.

LAFER, Celso. A reconstrução dos direitos humanos. Rio de Janeiro: Cia das Letras, 1991.

LEÓN, O. Democratização das comunicações. Disponível em <www.movimientos.org/foro_comunicacion>. Acessado: 20 jan. 2002.

MARTÍNEZ, E. Glosario: Ciência, Tecnologia y Desarrollo. In: MARTÍNEZ, E.; ALBORNOZ, M. (eds) Indicadores de ciência y tecnologia: estado del arte y perspectivas. Caracas/Venezuela: Nueva Sociedad. Unesco, 1998.

MASSARANI, L.; MOREIRA, I.C.; BRITO; F. Ciência e público: caminhos da divulgação científica no Brasil. Rio de Janeiro: Casa da Ciência - Centro Cultural de Ciência e Tecnologia da Universidade Federal do Rio de Janeiro. Fórum de Ciência e Cultura, 2002.

MENDONÇA, O.M.L. Psicologia escolar e educacional. Ciência no Globo Ciência, São Paulo, v.1, n.1, p.45-52, 1996.

MOTTA-ROTH, D. A popularização da ciência como prática social e discursiva. In: MOTTA-ROTH, D.; GIERING, M.E. (Org.). Discursos de popularização da ciência. Anais do Encontro do Núcleo de Estudos Avançados "Linguagem Cultura e Sociedade”- GT Labler, 2009. Santa Maria: LABLER-PPGL/UFSM, 2009.

MOTTA-ROTH, D.; MARCUZZO, P. Ciência na mídia: análise crítica de gênero de notícias de popularização científica. Revista brasileira linguistica aplicada., Belo Horizonte, v.10, n.3, 2010. Disponível em: <http://www. 
scielo.br/scielo.php?script=sci_arttext\&pid=S1984-6398201000030 0002\&lng=en\&nrm=iso > . Acessado: 27 out. 2012.

NERVO, A.A. John Stuart Mill e sociedades da informação: liberdade de imprensa, Estado e opinião pública. Revista Estudos em Jornalismo e Mídia, v.8, n.2, PUC-RS, 2011.

OLIVEIRA, I.M. Cultura política, direitos e política social. In: BOSCHETTI, I. (Org). Política social no capitalismo: tendências contemporâneas. 2.ed. São Paulo: Editora Cortez, 2009. p.109-129.

PERUZZO, C.M.K. Direito à comunicação comunitária, participação popular e cidadania. Revista ALAIC, 2011. Disponível em: <http://www.alaic.net/revistaalaic/index.php/alaic/article/viewFile/145/166>. Acessado: 25 out. 2012.

PARK, R.E. News as a Form of Knowledge. Society - Collective Behavior, News and Opinion, Sociology and Modern Society. Illinois: The Free Press, 1955. p.71-88.

POULANTZAS, N. O Estado, o poder e o socialismo. 4.ed. São Paulo: Graal, 2000.

RUTHERFORD, F.J.; ALGREEN, A. Science for all Americans. Nova York, Oxford University Press, 1990. Disponível em: <http://books.google.com.br/ books?hl=pt-BR\&lr=\&id=LKadiKAUljEC\&oi=fnd\&pg =PR7\&dq=+Science+fo $r+$ all+Americans\&ots=MVomclYwBs\&sig=VpVZ9XOK9CTEmLQBR7Z18IW 0lg\#v=onepage\&q\&f=false $>$. Acessado: 22 set. 2011.

SAENZ, T.W.; SOUZA PAULA, M.C. Considerações sobre indicadores de inovação para América Latina, v.27, n.8, p.430-437, ago. 2002. Disponível em: <http://www.scielo.org.ve/scielo. $\quad$ php?script=sci_arttext\&pid=S0378-18442002000800008\&lng=pt\&nrm=iso ISSN 0378-1844>. Acessado: 20 set. 2011.

SECLAENDER, A.L. O direito de ser informado - base do paradigma moderno do direito de informação. Estudos e Comentários - RDP - 99. sl. 1991.

SOLLA PRICE, D.J. Ciencia y tecnologia: distinciones e interrelaciones. In: BARRY (org.) Estudios sobre sociologia de la ciencia. Madrid: Alianza Editorial, 1980.

TRUJILLO F.A. Metodologia da ciência. 2.ed. Rio de Janeiro: Kennedy, 1974.

ZANCAN, G.T. Educação científica: uma prioridade nacional. São Paulo Perspec., São Paulo, v.14, n.3, jul. 2000. Disponível em: <http://www.scielo.br/scielo. php?scri pt=sci_arttext\&pid=S010288392000000300002\&lng=pt\&nrm=i so>. Acessado: 17 out. 2011. 


\section{NOTAS:}

1 Nela, a estabilidade social se reduziria, em diversos casos, à manutenção do fluxo informativo constante atrelado a diversas áreas do conhecimento (NERVO, 2011).

2 Disponível em:<http://uenf.br/cch/jornaluniversitario $>$.

3 Ver Marcelo Gantos, “Televisão universitária para Campos: Foco e amplitude de uma experiência para reinvenção do público”. In Gantos, M.C (2003) Campos em perspectiva, Ed. Papel Virtual, Campos do Goytacazes.

${ }^{4}$ A coleção tem como objetivo a coleta, a guarda e a difusão da produção intelectual brasileira (Lei de Depósito Legal de Publicações, n. ${ }^{\circ}$ 10.994, de 14 de dezembro de 2004) Biblioteca Nacional, RJ. Desde 2012 o JUOL faz parte desta coleção.

5 O município de Campos dos Goytacazes tem uma população estimada em 463.731 habitantes (IBGE 2010) espalhados numa superfície de $4.032 \mathrm{~km}^{2}$.

${ }^{6}$ O IGC compila num único índice uma série de parâmetros de qualidade da totalidade dos cursos de graduação e pós-graduação de cada instituição.

7 Disponível em:<www.ibge.gov.br/home/presidencia/noticias/noticia_visualiza.php?id_noti cia $=1780 \&$ \&id_pagina $=1>$.

8 O JUOL nesta nova etapa adapta-se como diretriz de suas ações o conceito de inovação promovido pelo Decreto $n^{\circ} 42.302$ de 12 de fevereiro de 2010 REGULAMENTA A LEI No 5.361 . No Art. $2^{\circ}$ do Decreto, consideram-se: I - inovação: o fomento a pesquisas ou estudos em prol da manutenção da vida humana, atendidos os preceitos éticos atinentes à matéria objeto da pesquisa ou do desenvolvimento da inovação; e a introdução de novidade ou aperfeiçoamento no ambiente produtivo ou social que resulte em novos processos, produtos ou serviços, bem como em ganho de qualidade ou produtividade em processos, produtos ou serviços já existentes, visando ampliar a competitividade no mercado ou melhorar as condições de vida da população do Estado do Rio de Janeiro. Somente serão considerados como inovação social aqueles processos, produtos ou serviços que promovam a inclusão social em sua fase de implantação de projeto piloto em área restrita e determinada e/ou transferência de tecnologia (grifo nosso).

9 Existem diversos exemplos sobre isso, como a teoria newtoniana que cedeu lugar a uma teoria relativística e a teoria da evolução de Darwin que passou por inúmeras transformações.

10 A compreensão deve ser entendida como algo que favoreça o desenvolvimento de capacidades cognitivas e promova uma mudança de visão sobre a natureza do fenômeno científico-tecnológico, bem como de seus produtos, criando condições para a participação social nos processos de tomada de decisão acerca da CT\&I.

11 O conhecimento científico, segundo a citação de Bourdieu (2008, pg.101) é "aquilo que sobreviveu às objeções e pode resistir às objeções futuras”. Ou seja, são as novidades e as notícias da ciência que chegam ao público, não cientistas, de várias maneiras e por vários canais.

12 Segundo Poulantzas (1986), o conceito de poder indica os efeitos sobre as relações existentes entre classes sociais. O poder não está situado fora da ideia de luta de classes. Quando se fala em poder do Estado, o que se indica é o poder de uma determinada classe, a cujo interesse o Estado corresponde sobre outras classes sociais.

13 Segundo Lafer (1991, p. 241), “A Declaração Francesa de 1789 já antecipara este direito, ao afirmar não apenas a liberdade de opinião - artigo 10 -, mas também a livre comunicação das ideias e opiniões, que é considerada, no artigo 11, um dos mais preciosos direitos do homem.".

14 Propõe-se aqui que seja abandonada então a ideia de igualdade como a única forma de atingir a cidadania. Mais importante, para este trabalho, é avançar na análise da relação da igualdade com as demandas de respeito a direitos (Oliveira, 2001).

${ }^{15}$ A notícia é resultado de uma complexa combinação. De acordo com Franciscato (2002), é resultado de "sua forma e conteúdo final representam a convergência de vários processos sociais (...), acentuados em complexidade pelos aspectos cultural, expressivo e emotivo impressos em sua 'materialidade', que lhe fazem assumir contornos (...) quase únicos". Assim, Park (1955, p. 82) acredita que o "valor noticioso é relativo" devido aos contornos e operacionalização dela. 
120 Revista ELO - Diálogos em Extensão Volume 02, número 01 - julho de 2013 